\title{
High-resolution Manometry: Esophageal Disorders Not Addressed by the "Chicago Classification”
}

\author{
Yu Tien Wang, ${ }^{*}$ Etsuro Yazaki and Daniel Sifrim \\ Barts and The London School of Medicine and Dentistry, Queen Mary University of London, London, United Kingdom
}

The development of the high-resolution esophageal manometry (HRM) and the Chicago classification have improved the diagnosis and management of esophageal motility disorders. However, some conditions have yet to be addressed by this classification. This review describes findings in HRM which are not included in the current Chicago classification based on the experience in our center. This includes the analysis of the upper esophageal sphincter, proximal esophagus, longitudinal muscle contraction, disorders related to gastroesophageal reflux disease and respiratory symptoms. The utility of provocative tests and the use of HRM in the evaluation of rumination syndrome and post-surgical patients will also be discussed. We believe that characterization of the manometric findings in these areas will eventually lead to incorporation of new criteria into the existing classification.

(J Neurogastroenterol Motil 2012;18:365-372)

Key Words

Chicago classification; Esophageal motility disorders; Manometry

\section{Introduction}

Esophageal manometry has enabled us to study the esophageal motility by measuring pressure profiles in the esophagus. The recent development of high-resolution esophageal manometry (HRM) has further enhanced our ability to study this in much greater detail by providing pressure measurements at more levels along the esophagus. The increase in the number of readings has also led to the use of color contour plots which allow a more intuitive representation of the measured pressure pattern. ${ }^{1}$
The development of the Chicago classification Criteria of Esophageal Motility Disorders, ${ }^{2,3}$ based on HRM, has improved the diagnosis and management of patients with motility-related esophageal symptoms. ${ }^{4,5}$ However, it is a work in progress which will eventually incorporate new categories of manometric abnormalities linked to patients' symptoms.

In clinical practice, one third of the patients referred to our unit for investigation of presumed pharyngo-esophageal-related complaints have findings in HRM which are not described by the Chicago classification (Fig. 1).

The HRM findings in the following areas will be discuss-

Received: August 21, 2012 Revised: September 22, 2012 Accepted: September 28, 2012

(c) This is an Open Access article distributed under the terms of the Creative Commons Attribution Non-Commercial License (http://creativecommons. org/licenses/by-nc/3.0) which permits unrestricted non-commercial use, distribution, and reproduction in any medium, provided the original work is properly cited.

*Correspondence: Yu Tien Wang, MBBS, MD

The Wingate Institute for Neurogastroenterology, Blizard Institute of Cell and Molecular Science, Center for Digestive Diseases, 26 Ashfield Street, London E1 2AJ, United Kingdom

Tel: +44-20-7882-2655, Fax: +44-20-7375-2103, E-mail: wangyutien@gmail.com

Financial support: None.

Conflicts of interest: None. 


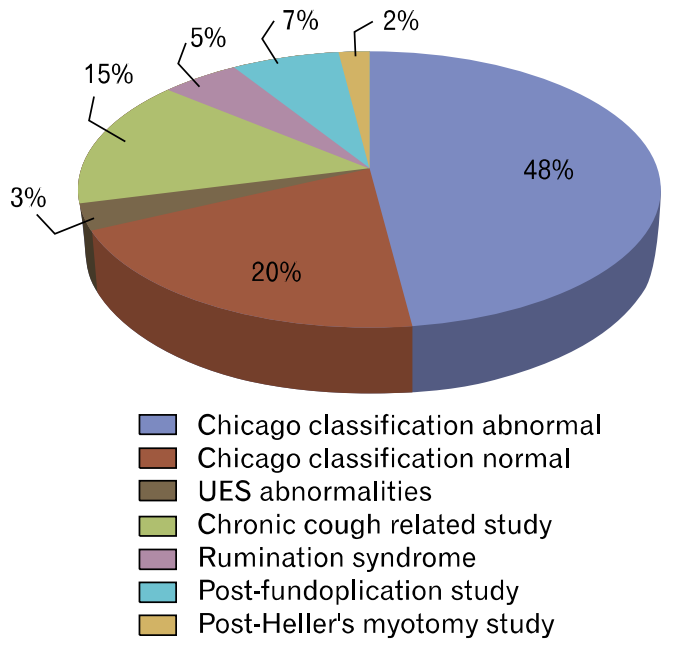

Figure 1. Pie-chart of high-resolution esophageal manometry diagnoses of 607 patients investigated at the Royal London Hospital Upper GI Physiology Unit in 2011 (unpublished data). UES, upper esophageal sphincter.

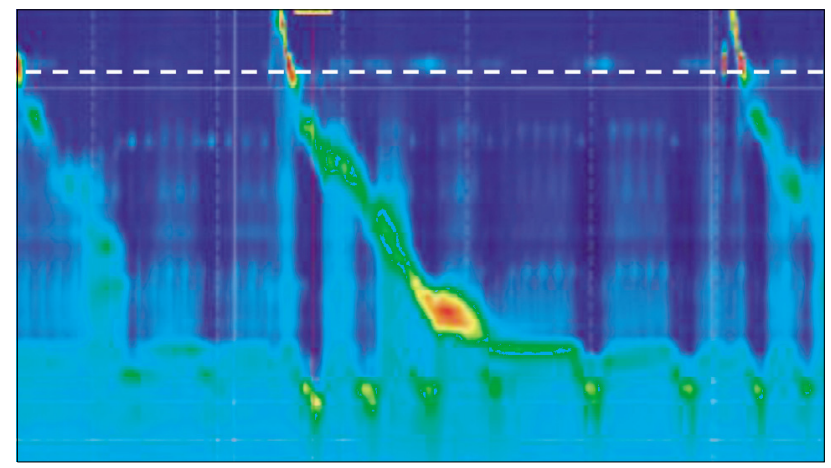

Figure 2. High-resolution esophageal manometry contour plot demonstrating a hypotensive upper esophageal sphincter (UES). The white dashed line shows the position of the UES.

ed:

(1) Upper esophageal sphincter

(2) Proximal esophagus (striated muscle)

(3) Longitudinal muscle contraction

(4) Disorders related to gastroesophageal reflux disease

(5) Disorders related to gastroesophageal respiratory disorders

(6) Provocative tests

(7) Rumination syndrome

(8) Post-surgical assessments in
A. Fundoplication
B. Achalasia treatments
C. Bariatric surgery

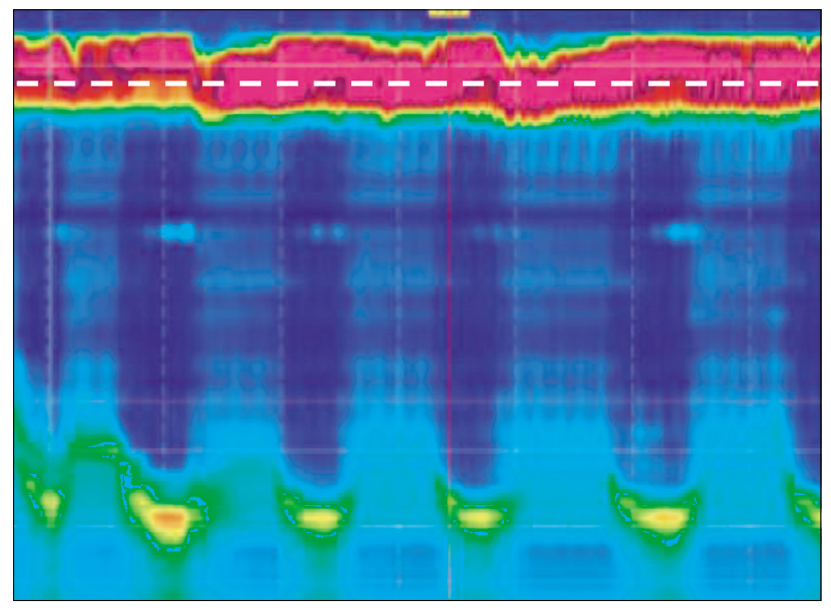

Figure 3. High-resolution esophageal manometry contour plot demonstrating a hypertensive upper esophageal sphincter (UES). The white dashed line shows the position of the UES.

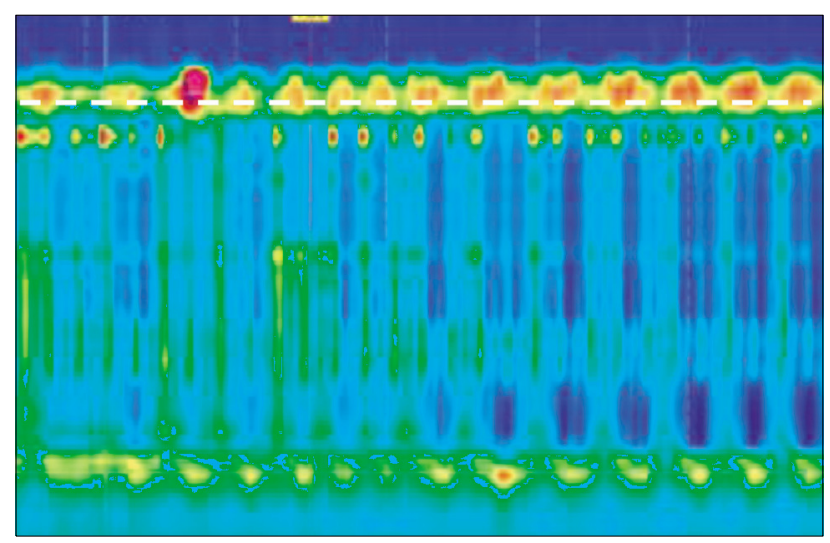

Figure 4. High-resolution esophageal manometry contour plot demonstrating a hyperdynamic upper esophageal sphincter (UES). The white dashed line shows the position of the UES.

\section{Upper Esophageal Sphincter}

The upper esophageal sphincter (UES) is represented by a 3 $\mathrm{cm}$ high pressure zone between the pharynx and the proximal esophagus. It consists of skeletal muscles which relax in a coordinated manner in relation to pharyngeal and proximal esophageal contraction during deglutition. Dysphagia and other cervical symptoms such as globus may be a result of disorders of the UES. Evaluation of the UES may identify abnormalities in the baseline pressures, impaired relaxation during swallows or hyperdynamic UES (large pressure variation caused by respiration). The latter is associated with the globus sensation (Fig. 2-4). ${ }^{6}$ 


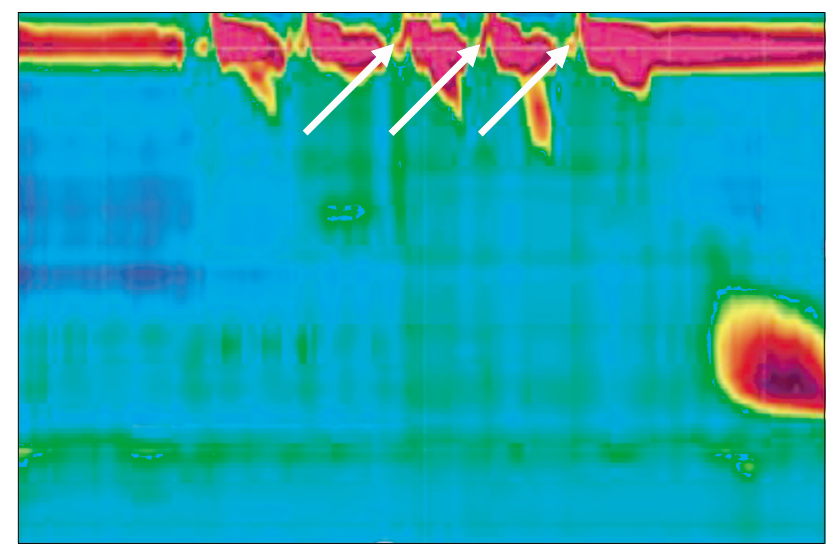

Figure 5. High-resolution esophageal manometry contour plot demonstrating a cricopharyngeal bar. The white arrows show raised intrabolus pressure.

Compartmentalized pressurization near the UES during swallows may suggest anatomical abnormalities such as a cricopharyngeal bar (Fig. 5). ${ }^{7}$ Recently, an automated analysis of pharyngeal and UES manometry has been proposed ${ }^{8}$ which would enable a standardized study protocol.

As esophageal intubation may cause elevated UES pressure, care should be taken to allow adequate recovery time before UES measurements are made. In our centre, this is done by performing the UES measurements at the end of the study, whereby we then re-position the HRM catheter to allow adequate visualization of the UES and adjacent structures.

\section{Proximal Esophagus}

While the Chicago classification has extensively characterized contractions of the distal smooth muscle esophagus and the length of transitional zone, pathology of proximal (striated muscles) esophageal motility has not been described. We have encountered patients with weak or absent proximal esophageal contractions but normal distal esophageal motility (Fig. 6). The clinical relevance of this finding is unknown. Indeed, many of these patients had no dysphagia or related systemic disorders. However, previous studies with standard manometry have described abnormalities affecting only striated muscles of the esophagus such as myasthenia gravis ${ }^{9}$ and polymyositis. ${ }^{10}$

\section{Longitudinal Muscle Contraction}

Longitudinal muscle contraction of the esophagus is important in the pathophysiology of functional esophageal diseases. ${ }^{11}$ However, pressure changes which are detected by HRM measure mainly circular muscle contractions of the esophagus.

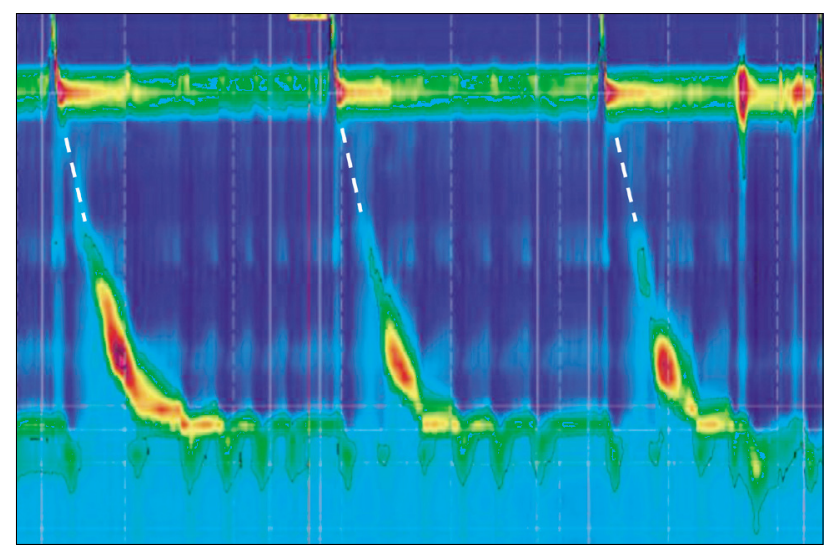

Figure 6. High-resolution esophageal manometry contour plot demonstrating absent proximal esophageal contraction. The white dashed lines show the usual position of proximal esophageal contractions.

Longitudinal contractions may be visualized by "esophageal shortening" where the lower esophageal sphincter (LES) is seen to be lifted upwards during deglutition (Fig. 7). ${ }^{12,13}$ Studies have suggested that prolonged contractions of the longitudinal esophageal muscle may be related to non-cardiac chest pain and reflux disease. ${ }^{14,15}$ Longitudinal muscle contraction may also result in the "pseudorelaxation" appearance in HRM as a result of lifting the LES. It is important to make corresponding adjustments to enable correct measurements of the integrated relaxation pressure, an important parameter to evaluate esophagogastric junction relaxation using HRM. It is also possible to diagnose esophageal shortening-related symptoms using an ambulatory HRM system. ${ }^{16}$

\section{Disorders Related to Gastroesophageal Refl- ux Disease}

The Chicago classification describes manometric abnormalities which are associated with dysphagia. In addition to those diagnoses, HRM may also identify abnormalities which predispose patients to pathological gastroeosphageal reflux disease (GERD).

The distal high pressure zone (DHPZ) is a $3-4 \mathrm{~cm}$ high-pressure zone at the distal esophagus that acts as an anti-reflux barrier, constituted by the LES and the crural diaphragm. Pathology which compromises the DHPZ such as hypotensive LES, hiatus hernia and increased number of transient lower esophageal sphincter relaxation (TLESR) predisposes the patient to increased gastro-esophageal reflux. Hiatus hernia is caused by the sliding of the stomach into the thoracic cavity. This results in the separation of the LES from the crura at the DHPZ which reduces the efficacy of the anti-reflux barrier (Fig. 8). 


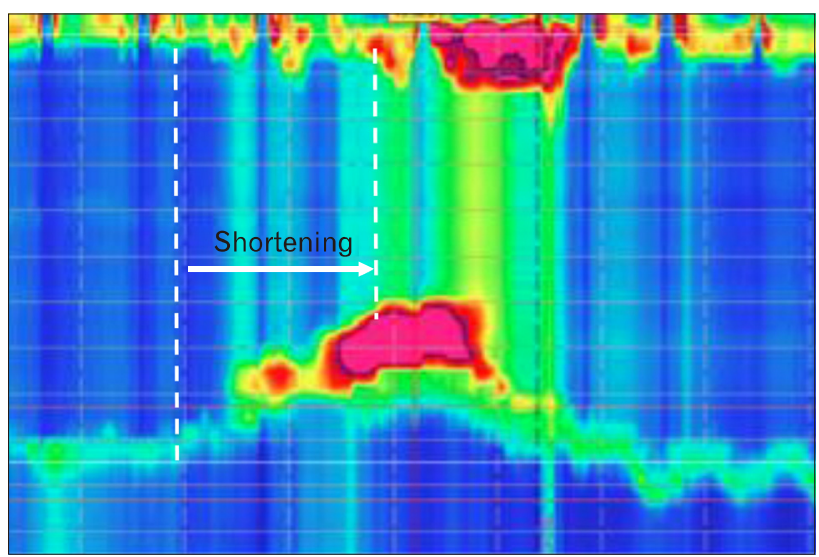

Figure 7. High-resolution esophageal manometry contour plot demonstrating esophageal shortening. The white dashed lines show esophageal lengths and shortening during longitudinal contraction.

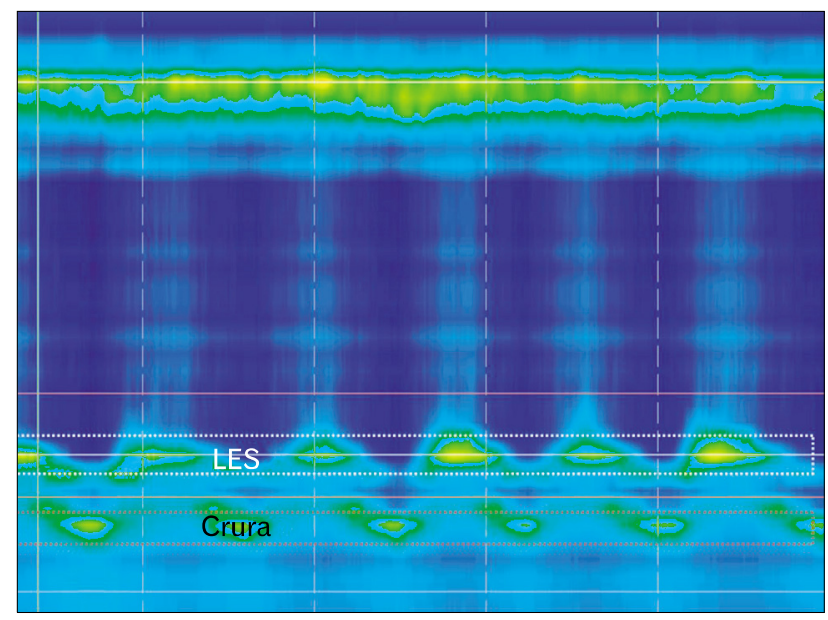

Figure 8. High-resolution esophageal manometry contour plot of hiatus hernia. White dotted box, lower esophageal sphincter (LES); red dotted box, Crura.

TLESR is the spontaneous relaxations of the LES triggered by vagal reflex, independent of swallowing (Fig. 9). ${ }^{17}$ It is a vagal reflex triggered by gastric distension and/or pharyngeal or laryngeal stimulation. In patients with normal LES pressure, it is the most common mechanism of gastroesophageal reflux. ${ }^{18,19}$ HRM also allows a precise measurement of gastroesophageal pressure gradients (GEPG). For example, in a recent study. For example, in a recent study we found that increased GEPG was associated with increased GEPG d post-prandial reflux in a group of patients with cystic fibrosis. In these patients, this was

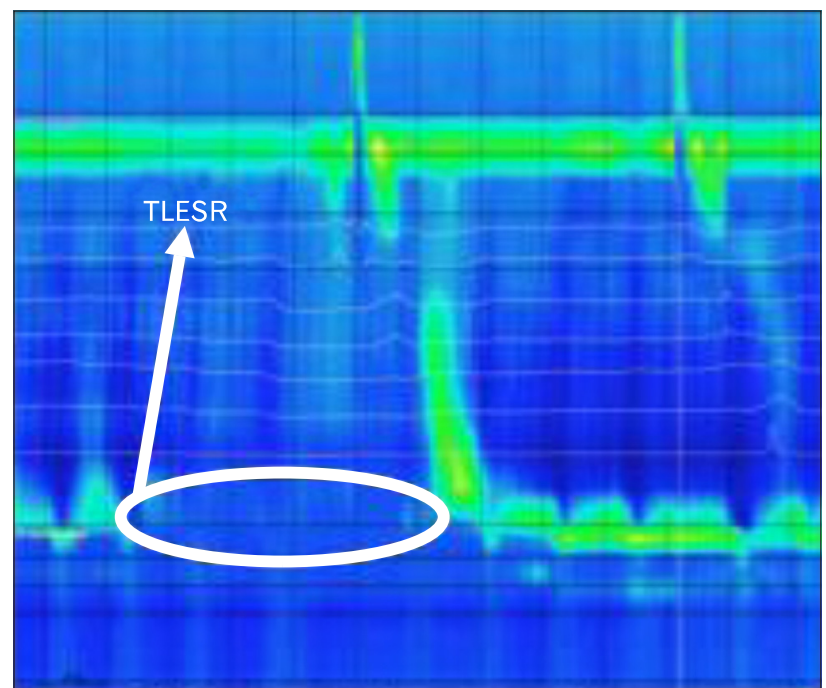

Figure 9. High-resolution esophageal manometry contour plot of transient lower esophageal sphincter relaxation (TLESR).

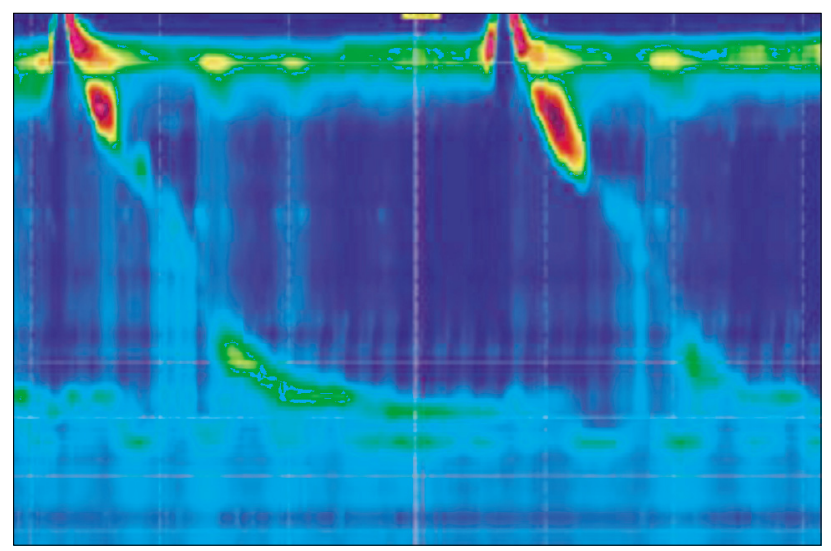

Figure 10. High-resolution esophageal manometry contour plot of esophageal hypomotility.

caused by increased negative inspiratory intra-thoracic pressure. ${ }^{20}$

Esophageal body hypomotility (Fig. 10) can be associated with increased nocturnal acid exposure due to ineffective clearance of acid reflux. ${ }^{21}$

Identifying the above abnormalities in GERD patients enable management to be directed at their respective pathophysiology.

\section{Disorders Related to Respiratory Symptoms}

GERD has been shown to be associated with respiratory symptoms and is thought to be the 3 rd most common cause of chronic cough. ${ }^{22}$ Whilst the exact pathophysiology is still unclear, 


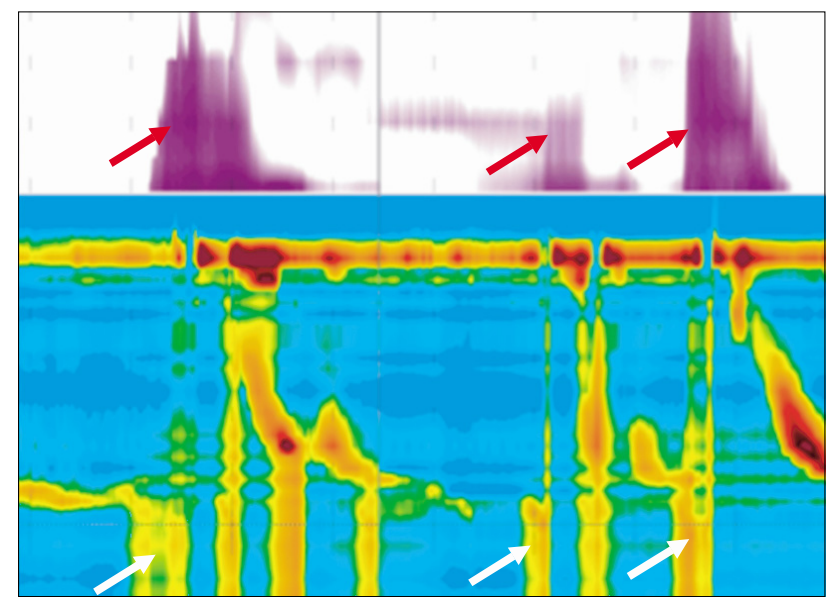

Figure 11. Combined High-resolution esophageal manometry-impedance monitoring demonstrating rumination. White arrows show raised intragastric pressure. Red arrows show retrograde movement of liquid.

it has been proposed that esophageal acid exposure, laryngopharyngeal reflux or microaspiration of refluxate into the lung could directly provoke cough or indirectly result in sensitization of the cough reflex, such that cough could be more easily provoked by common environmental stimuli. ${ }^{23}$ Hypotensive LES and esophageal hypomotility has been associated with increased respiratory symptoms such as nocturnal cough and asthma, ${ }^{24,25}$ possibly by predisposition to the earlier-mentioned mechanisms. The use of HRM in addition to 24-hour combined pH-impedance monitoring may reveal esophageal motility disorders that can predispose to or be part of a systemic disease (scleroderma or pulmonary fibrosis) that underlies chronic respiratory symptoms.

\section{Rumination Syndrome}

Rumination syndrome is a functional disorder characterized by recurrent regurgitation of ingested food back into the mouth. The diagnosis is based on Rome III criteria. ${ }^{26}$ Using combined HRM-impedance monitoring, the diagnosis is supported by identifying raised intragastric pressure generated by voluntary abdominal contractions (absence of retching), which in turn produces retrograde movement of gastric contents through the esophagus (Fig. 11). Recently, combined HRM-impedance monitoring was effectively used to distinguish between rumination and supragastric belching. ${ }^{27}$

\section{Provocative Tests}

The Chicago classification is based on analysis of ten $5 \mathrm{~mL}$ water swallows. However many patient with esophageal symp-

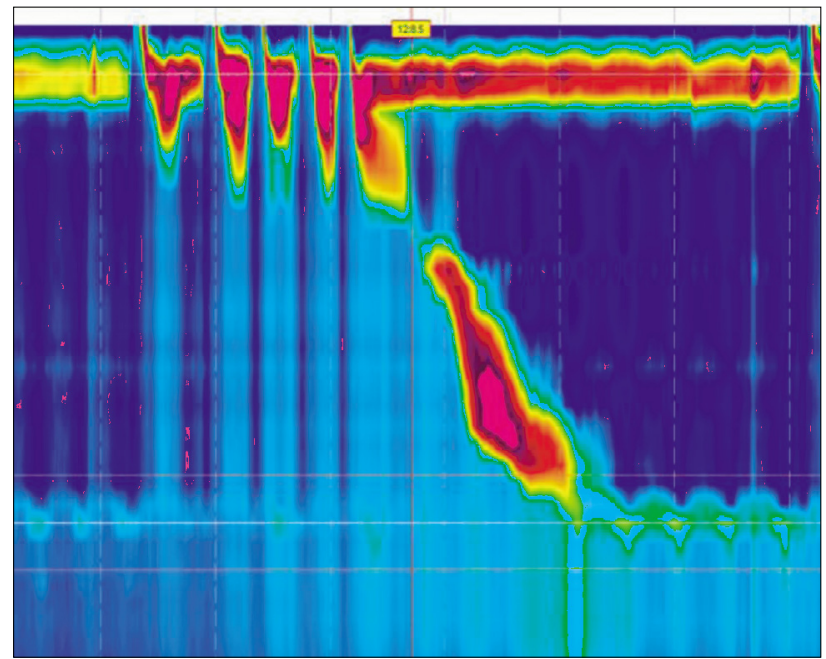

Figure 12. High-resolution esophageal manometry of multiple rapid swallows.

toms have normal HRM findings and do not experience symptoms with these small volume water swallows. ${ }^{28}$ The use of complementary provocative tests which includes the use of multiple rapid swallows (MRS) and solid swallows has been shown to increase sensitivity of detecting motility disorders. ${ }^{29-31}$

MRS (Fig. 12) examines the integrity of inhibitory and excitatory mechanisms which regulate esophageal motility and esophageal muscle integrity. This is achieved by demonstrating absence of esophageal smooth muscle contractions during the swallows and the ability to mount a strong after-contraction at the end of the MRS. ${ }^{32-34}$ It is performed by 5 swallows of $3 \mathrm{~mL}$ water each (in 2-3 second intervals) which is directly injected into the patient's mouth. This test was shown to demonstrate abnormality in $67 \%$ of patients with esophageal symptoms and normal manometry on single water swallows. The ability of patients with esophageal hypomotility to mount a normal after-MRS response also demonstrates intact muscular integrity which may predict response to cholinergic prokinetic treatment. A recent study also showed that abnormal MRS can predict post-operative dysphagia in patients undergoing anti-reflux surgery. ${ }^{35}$

Solid swallows are performed using $1 \mathrm{~cm}^{3}$ bread swallows and normative values have been established previously. ${ }^{36}$ In clinical practice, solid swallows are difficult to analyze because it generates complex pressure patterns and the food boluses are often not transported in one single swallow. However, HRM abnormalities detected during the investigation which triggers the patient's presenting complaint would provide direct pathophysiological diagnoses for their symptoms. 


\section{Post-surgical Assessments}

Patients who have undergone surgical procedures have altered anatomies and functions which generate HRM pressure profiles beyond the normal parameters set by the Chicago classification.

Fundoplication alters the configuration of the DHPZ. HRM is useful for evaluation of post-fundoplication patients with recurrence of GERD symptoms or development of new upper gastrointestinal symptoms by analyzing the strength of the DHPZ and relative positions of the LES and the fundoplication wrap. The various configurations of the $\mathrm{DHPZ}$ with corresponding positions of the LES and the fundoplication wrap were recently described. ${ }^{37}$ In summary, an elevated single DHPZ at the LES correlates with an intact and appropriately-positioned fundoplication when there is normal pressure and relaxation. An elevated single DHPZ at the LES with low pressure and normal relaxation suggests disrupted fundoplication while with high pressure and incomplete relaxation, it suggests a twisted fundoplication. The presence of a dual DHPZ indicates an inappropriate position of fundoplication (Fig. 13).

Achalasia is a primary esophageal motility disorder which is characterized by defective relaxation of the LES and absence of esophageal peristalsis resulting in dysphagia, regurgitation and chest pain. ${ }^{38}$ Management involves mechanical disruption of LES muscle fibers by surgical myotomy or pneumatic dilatation. ${ }^{39}$ Successful treatment can be demonstrated on HRM by the loss of the DHPZ (Fig. 14A). Resting LES pressure of more than $10 \mathrm{mmHg}$ and reduction of less than $50 \%$ from baseline are factors predictive of treatment failure and recurrence of symptoms (Fig. 14B), ${ }^{40,41}$ although distensibility of the LES measured with the endoscopic functional luminal imaging probe (EndoFLIP) has recently been shown to be a better predictor of treatment outcome. ${ }^{42}$

Bariatric surgery which alters anatomy may result in side effects like dysphagia, vomiting or reflux. Studies in laparoscopic adjustable gastric bands (LAGB) which assess the transition of peristaltic waves to a sustained LES after-contraction have shown that hypotensive distal esophageal contractions and the absence of the lower esophageal contractile segment is predictive of side effects. ${ }^{43}$ HRM may also detect anatomical abnormalities such as obstruction secondary to paraprosthetic fibrosis in patients who underwent LAGB which is demonstrated by the presence of a gastric high pressure zone after removal of the gastric band. ${ }^{44}$

\section{Conclusion}

The development of the Chicago classification Criteria of Esophageal Motility Disorders, ${ }^{2,3}$ based on HRM, has significantly improved the diagnosis and management of patients with motility-related esophageal symptoms but remains an evolutionary process.

The understanding of the basic structures and physiology of the esophagus as well as their changes in diseases and surgical
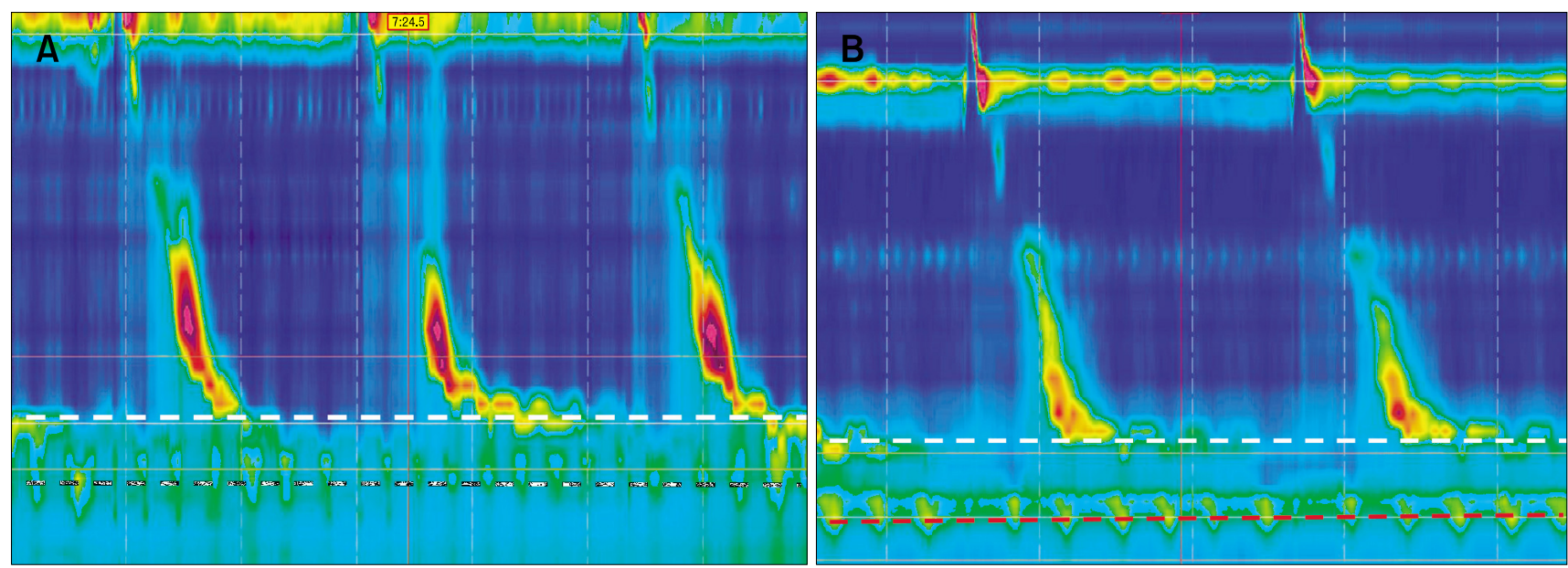

Figure 13. (A) Pre-fundoplication high-resolution esophageal manometry (HRM) showing hypotensive lower esophageal sphincter (LES) and hiatus hernia. The white dashed line shows a hypotensive LES. The black dashed line shows the diaphragmatic crura. (B) Post-fundoplication HRM showing dual high pressure zones suggesting a slipped fundoplication wrap. The white dashed line shows LES. The red dashed line shows the fundoplication wrap. 

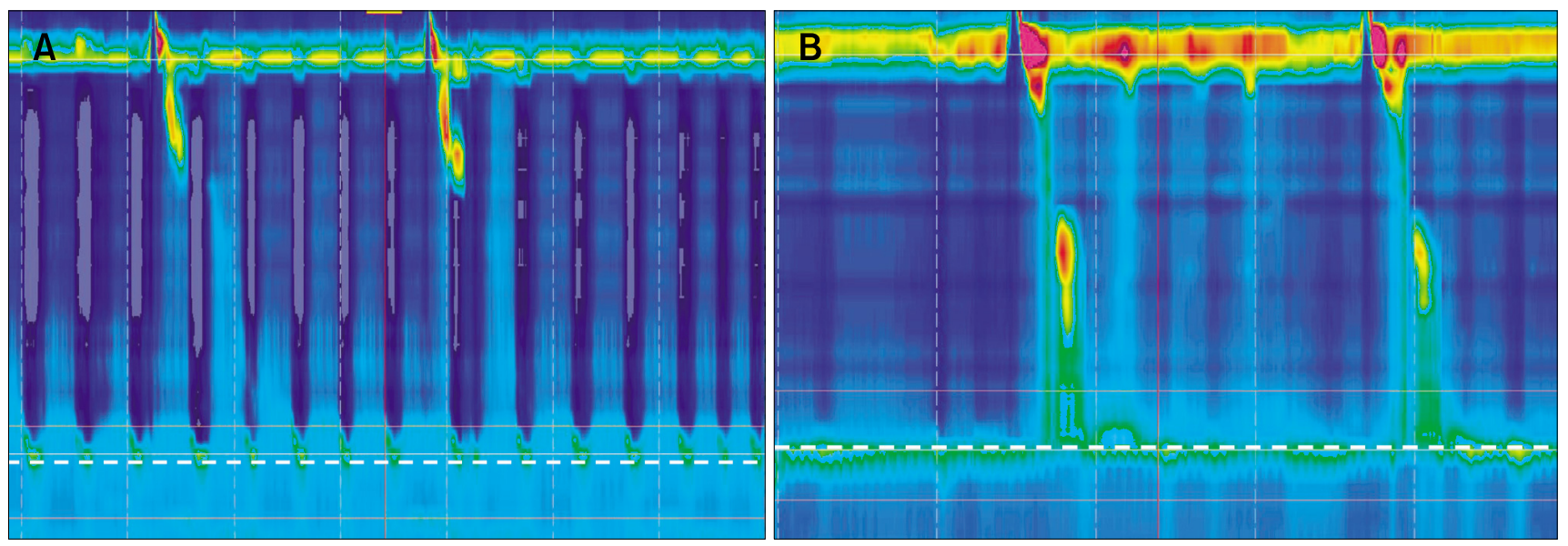

Figure 14. (A) High-resolution esophageal manometry (HRM) showing ablation of lower esophageal sphincter (LES) pressure in a patient with achalasia who underwent successful myotomy. The white dashed line shows a non-relaxing LES with low pressure. (B) HRM showing persistently high basal LES pressure in a patient with achalasia who has persistent symptoms post-myotomy. The white dashed line shows a non-relaxing LES with high basal pressure.

procedures will enable the use of HRM for a wide spectrum of conditions beyond those defined by the current classification. We believe that characterization of the manometric findings in these conditions will eventually lead to incorporation of new criteria for the diagnoses of pharyngo-esophageal disorders into the classification.

\section{References}

1. Clouse RE, Staiano A. Topography of the esophageal peristaltic pressure wave. Am J Physiol 1991;261(4 Pt 1):G677-G684.

2. Kahrilas PJ, Ghosh SK, Pandolfino JE. Esophageal motility disorders in terms of pressure topography: the Chicago classification. J Clin Gastroenterol 2008;42:627-635.

3. Bredenoord AJ, Fox M, Kahrilas PJ, et al. Chicago classification criteria of esophageal motility disorders defined in high resolution esophageal pressure topography. Neurogastroenterol Motil 2012; 24(suppl 1):57-65.

4. Salvador R, Costantini M, Zaninotto $G$, et al. The preoperative manometric pattern predicts the outcome of surgical treatment for esophageal achalasia. J Gastrointest Surg 2010;14:1635-1645 .

5. Pratap N, Kalapala R, Darisetty S, et al. Achalasia cardia subtyping by high-resolution manometry predicts the therapeutic outcome of pneumatic balloon dilatation. J Neurogastroenterol Motil 2011;17: 48-53.

6. Kwiatek MA, Mirza F, Kahrilas PJ, Pandolfino JE. Hyperdynamic upper esophageal sphincter pressure: a manometric observation in patients reporting globus sensation. Am J Gastroenterol 2009;104: 289-298.

7. Hirano I, Kahrilas PJ. A 78-year-old man with difficulty swallowing. Clin Gastroenterol Hepatol 2011;9:470-474.

8. Mielens JD, Hoffman MR, Ciucci MR, Jiang JJ, McCulloch TM. Automated analysis of pharyngeal pressure data obtained with high-resolution manometry. Dysphagia 2011;26:3-12.

9. Huang MH, King KL, Chien KY. Esophageal manometric studies in patients with myasthenia gravis. J Thorac Cardiovasc Surg 1988; 95:281-285.

10. Joshita Y, Yoshida Y, Kimura K, Yoshida M. [Manometrical study of the pharynx and the pharyngoesophageal sphincter in patients with polymyositis.] Nihon Shokakibyo Gakkai Zasshi 1991;88:651-658. [Japanese]

11. Mittal RK, Liu J, Puckett JL, et al. Sensory and motor function of the esophagus: lessons from ultrasound imaging. Gastroenterology 2005;128:487-497.

12. Tutuian R, Pohl D, Castell DO, Fried M. Clearance mechanisms of the aperistaltic oesophagus: the "pump gun" hypothesis. Gut 2006; 55:584-585.

13. Pandolfino JE, Kwiatek MA, Nealis T, Bulsiewicz W, Post J, Kahrilas PJ. Achalasia: a new clinically relevant classification by high-resolution manometry. Gastroenterology 2008;135:1526-1533.

14. Balaban DH, Yamamoto Y, Liu J, et al. Sustained esophageal contraction: a marker of esophageal chest pain identified by intraluminal ultrasonography. Gastroenterology 1999;116:29-37.

15. Pehlivanov N, Liu J, Mittal RK. Sustained esophageal contraction: a motor correlate of heartburn symptom. Am J Physiol Gastrointest Liver Physiol 2001;281:G743-G751.

16. Mittal RK, Karstens A, Leslie E, Babaei A, Bhargava V. Ambulatory high-resolution manometry, lower esophageal sphincter lift and transient lower esophageal sphincter relaxation. Neurogastroenterol Motil 2012;24:40-46. e2.

17. Mittal RK, McCallum RW. Characteristics of transient lower esophageal sphincter relaxation in humans. Am J Physiol 1987;252(5 Pt 1):G636-G641.

18. Mittal RK, McCallum RW. Characteristics and frequency of transient relaxations of the lower esophageal sphincter in patients with reflux esophagitis. Gastroenterology 1988;95:593-599.

19. Dodds WJ, Dent J, Hogan WJ, et al. Mechanisms of gastroesophageal reflux in patients with reflux esophagitis. $\mathrm{N}$ Engl $\mathrm{J}$ Med 
1982;307:1547-1552.

20. Pauwels A, Blondeau K, Dupont LJ, Sifrim D. Mechanisms of increased gastroesophageal reflux in patients with cystic fibrosis. Am J Gastroenterol 2012;107:1346-1353.

21. Fornari F, Blondeau K, Durand L, et al. Relevance of mild ineffective oesophageal motility (IOM) and potential pharmacological reversibility of severe IOM in patients with gastro-oesophageal reflux disease. Aliment Pharmacol Ther 2007;26:1345-1354.

22. Pauwels A, Blondeau K, Dupont L, Sifrim D. Cough and gastroesophageal reflux: from the gastroenterologist end. Pulm Pharmacol Ther 2009;22:135-138.

23. Smith J, Woodcock A, Houghton L. New developments in reflux-associated cough. Lung 2010;188(suppl 1):S81-S86.

24. Machado Mda M, Cardoso PF, Ribeiro IO, Zamin Júnior, Eilers RJ. Esophageal manometry and 24-h esophageal $\mathrm{pH}$-metry in a large sample of patients with respiratory symptoms. J Bras Pneumol 2008;34:1040-1048.

25. Sweet MP, Patti MG, Leard LE, et al. Gastroesophageal reflux in patients with idiopathic pulmonary fibrosis referred for lung transplantation. J Thorac Cardiovasc Surg 2007;133:1078-1084.

26. Tack J, Talley NJ, Camilleri M, et al. Functional gastroduodenal disorders. Gastroenterology 2006;130:1466-1479.

27. Blondeau K, Boecxstaens V, Rommel N, et al. Baclofen improves symptoms and reduces postprandial flow events in patients with rumination and supragastric belching. Clin Gastroenterol Hepatol 2012;10:379-384.

28. Fox MR, Bredenoord AJ. Oesophageal high-resolution manometry: moving from research into clinical practice. Gut 2008;57:405-423.

29. Allen ML, Mellow MH, Robinson M. Manometry during food ingestion aids in the diagnosis of diffuse esophageal spasm. Am J Gastroenterol 1992;87:568-571.

30. Fornari F, Bravi I, Penagini R, Tack J, Sifrim D. Multiple rapid swallowing: a complementary test during standard oesophageal manometry. Nerogastroenterol Motil 2009;21:718-e41.

31. Bernhard A, Pohl D, Fried M, Castell DO, Tutuian R. Influence of bolus consistency and position on esophageal high-resolution manometry findings. Dig Dis Sci 2008;53:1198-1205.

32. Ask P, Tibbling L. Effect of time interval between swallows on esophageal peristalsis. Am J Physiol 1980;238:G485-G490.
33. Behar J, Biancani P. Pathogenesis of simultaneous esophageal contractions in patients with motility disorders. Gastroenterology 1993; 105:111-118.

34. Meyer GW, Gerhardt DC, Castell DO. Human esophageal response to rapid swallowing: muscle refractory period or neural inhibition? Am J Physiol 1981;241:G129-G136.

35. Stoikes N, Drapekin J, Kushnir V, Shaker A, Brunt LM, Gyawali $\mathrm{CP}$. The value of multiple rapid swallows during preoperative esophageal manometry before laparoscopic antireflux surgery. Surg Endosc Published Online First: 31 May 2012.

36. Sweis R, Anggiansah A, Wong T, Kaufman E, Obrecht S, Fox M. Normative values and inter-observer agreement for liquid and solid bolus swallows in upright and supine positions as assessed by esophageal high-resolution manometry. Neurogastroenterol Motil 2011; 23:509-e198.

37. Hoshino M, Srinivasan A, Mittal SK. High-resolution manometry patterns of lower esophageal sphincter complex in symptomatic postfundoplication patients. J Gastrointest Surg 2012;16:705-714.

38. Boeckxstaens GE. Achalasia. Best Pract Res Gastroenterol 2007; 21:595-608.

39. Richter JE, Boeckxstaens GE. Management of achalasia: surgery or pneumatic dilation. Gut 2011;60:869-876.

40. Eckardt VF, Gockel I, Bernhard G. Pneumatic dilation for achalasia: late results of a prospective follow up investigation. Gut 2004;53: 629-633.

41. Ghoshal UC, Kumar S, Saraswat VA, Aggarwal R, Misra A, Choudhuri G. Long-term follow-up after pneumatic dilation for achalasia cardia: factors associated with treatment failure and recurrence. Am J Gastroenterol 2004;99:2304-2310.

42. Rohof WO, Hirsch DP, Kessing BF, Boeckxstaens GE. Efficacy of treatment for patients with achalasia depends on the distensibility of the esophagogastric junction. Gastroenterology 2012;143:328-335.

43. Burton PR, Brown WA, Laurie C, Hebbard G, O'Brien PE. Criteria for assessing esophageal motility in laparoscopic adjustable gastric band patients: the importance of the lower esophageal contractile segment. Obes Surg 2010;20:316-325.

44. Vallin M, Robert M, Roman S, Mion F, Poncet G. Persistent dysphagia after removal of an adjustable gastric band for morbid obesity: a rare complication. Dis Esophagus 2011;24:401-403. 